\section{(A) Check for updates}

Cite this: Food Funct., 2022, 13, 1370

\title{
Influence of the particle size of encapsulated chia oil on the oil release and bioaccessibility during in vitro gastrointestinal digestion $\uparrow$
}

\author{
Rudy Álvarez, (D) a Begoña Giménez, (DD ${ }^{\mathrm{b}}$ Alan Mackie, (D) ${ }^{\mathrm{c}}$ Amelia Torcello-Gómez, ${ }^{\mathrm{c}}$ \\ Alejandra Quintriqueo, (D) ${ }^{a}$ Felipe Oyarzun-Ampuero (D) ${ }^{d}$ and Paz Robert (D) *a
}

\begin{abstract}
Among vegetable oils, chia oil has been gaining interest in recent years due to its high linolenic acid content (ALA, 18:3 $\mathrm{\omega} 3$ ). The aim of this work was to study the influence of the particle size of encapsulated purified chia oil (PCO) on the encapsulation efficiency and PCO release during in vitro digestion. PCO micro- and nano-sized particles with sodium alginate (SA) as an encapsulating agent (ME-PCO-SA and NE-PCO-SA) were designed by micro and nano spray-drying, respectively, applying a central composite plus star point experimental design. NE-PCO-SA showed a smaller particle size and higher encapsulation efficiency of PCO than ME-PCO-SA $(0.16 \mu \mathrm{m}$ vs. $3.5 \mu \mathrm{m} ; 98.1 \%$ vs. 92.0\%). Emulsions (NE-PCO and ME-PCO) and particles (NE-PCO-SA and ME-PCO-SA) were subjected to in vitro static gastrointestinal digestion. ME-PCO and NE-PCO showed sustained oil release throughout the three phases of digestion (oral, gastric and intestinal phases), whereas the PCO release from ME-PCO-SA and NE-PCO-SA occurred mainly in the intestinal phase, showing the suitability of sodium alginate as an intestine-site release polymer. Nano-sized particles showed a significantly higher PCO release after in vitro digestion (NE-PCO-SA, 78.4\%) than micro-sized particles (ME-PCO-SA, 69.8\%), and also higher bioaccessibility of individual free fatty acids, such as C18:3 $\omega-3$ (NE-PCO-SA, 23.6\%; ME-PCO-SA, 7.9\%), due to their greater surface area. However, when ME-PCO-SA and NE-PCO-SA were incorporated into yogurt, the PCO release from both particle systems after the digestion of the matrix was similar (NE-PCO-SA, 58.8\%; ME-PCO-SA-Y, 61.8\%), possibly because the calcium ions contained in the yogurt induced partial ionic gelation of SA, impairing the PCO release. Sodium alginate spray-dried micro and nanoparticles showed great potential for vehiculation of omega-3 rich oils in the design of functional foods.
\end{abstract}

Received 2nd November 2021, Accepted 13th December 2021 DOI: $10.1039 / \mathrm{d} 1 \mathrm{fo} 03688 \mathrm{~b}$

rsc.li/food-function increasing demand for sources of omega-3 fatty acids such as $\alpha$-linolenic acid (ALA, 18:3 $\omega 3$ ) from plant-based sources. ${ }^{1}$ ALA is a precursor of EPA and DHA, but the bioconversion is minimal. However, several studies have reported the independent role of ALA on human health. Thus, several beneficial effects on health have been described for ALA, such as cardiovascular-protective, anti-inflammatory, anti-cancer, neuroprotective and anti-osteoporotic. ${ }^{2}$ Chia oil has the highest content of ALA $(\sim 65 \%)$ among the vegetable oils. However, polyunsaturated oils are susceptible to oxidative and hydrolytic degradation due to their structural features, with two or three double bonds, when exposed to the environment, food and gastrointestinal conditions. ${ }^{3,4}$

Encapsulation is a technology based on coating or entrapping solid, liquid or gaseous materials, which can be used to protect, transport or control the release of active compounds. ${ }^{5}$ Spray-drying is the most common method for oil encapsulation, ${ }^{3}$ such as chia oil. ${ }^{6-17}$ In these studies, chia oil encapsulation has been mainly focused on protecting polyunsaturated 
fatty acids from the environmental conditions (light, oxygen, temperature and water), to stabilize the oil, avoiding its oxidation. Different strategies involving the selection of biopolymers as encapsulating agents, spray-dryer operating conditions and storage conditions of the microparticles have been evaluated. Thus, the mixture of polysaccharides (maltodextrin with different dextrose equivalents, Hi-Cap ${ }^{\circledR} 100$, pectin) with proteins (whey protein concentrate, whey protein isolate, sodium caseinate, skim milk protein, soy protein isolate and pea protein) or gums (Arabic gum and mesquite gum) gives microparticles with enhancing properties compared to the use of a single biopolymer. Proteins have good emulsifying properties to stabilize the oil-in-water emulsion required for the encapsulation of oils by spray-drying, whereas polysaccharides have good film-forming ability.

In vitro gastrointestinal digestion models are the most widely used models to assess the performance of several bioactive compound delivery systems under gastrointestinal conditions, such as lipid-based and biopolymer-based delivery systems. ${ }^{18}$ However, methodological differences among these models make the comparison of results among studies difficult. In this context, a standardized static in vitro digestion method (INFOGEST) was developed by international consensus, as a simulation of adult gastrointestinal digestion suitable for food..$^{19,20}$ The microencapsulated oils are expected to resist the adverse gastrointestinal environment, preserving the structure and functionality of polyunsaturated fatty acids, and to enable their release once the absorption site is reached, increasing their bioaccessibility. Studies of ALA-rich chia oil microparticles focussed on the design of delivery systems for intestinal release are scarce, ${ }^{11,21}$ reporting a low chia oil release during the intestinal phase of digestion. In this context, it is a challenge to design ALA-rich chia oil microparticles as site-specific oil delivery systems, targeted to the small intestine where lipids are absorbed, preserving its functionality. The selection of the encapsulating agent is an essential key to achieve specific-site delivery. Sodium alginate (SA) is a linear polysaccharide composed of alternating blocks of 1-4 linked $\alpha$-L-guluronic and $\beta$-D-mannuronic acid residues capable of forming a gel structure. SA is stable at acidic $\mathrm{pH}$ but dissolves under mild alkaline conditions, and therefore, the structure of SA remains intact in the stomach (acidic pH), but it swells and disintegrates in the small intestine (neutral $\mathrm{pH}$ ), releasing the active compounds. ${ }^{22}$ On the other hand, the particle size of the spray-dried powder may also have an effect on the bioaccessibility of the bioactive compounds during digestion, as it has been reported for other bio-based delivery systems. ${ }^{18,23}$ In this regard, nano spray-drying and conventional spray-drying are two spray-drying methodologies that offer the opportunity to study the effect of the particle size on the bioaccessibility of chia oil during in vitro simulated digestion, since nano spray-drying allows smaller particle sizes and narrower particle size distributions than conventional spraydrying. ${ }^{24}$ The smaller the particle size the greater the surface area exposed to pancreatic lipase during digestion, which should influence the release of chia oil from the particles and, therefore, the bioaccessibility of ALA. To the best of our knowledge, the encapsulation of chia oil with sodium alginate by conventional and nano spray-drying has not yet been studied.

This work aimed to study the influence of the particle size (micro- and nano-sized particles) of encapsulated chia oil with SA by spray-drying on the encapsulation parameters, physicochemical properties of the particles and the bioaccessibility of chia oil during in vitro gastrointestinal digestion. Furthermore, micro and nanoparticles of chia oil were incorporated into yogurt, and the chia oil release over time and under in vitro gastrointestinal conditions were also evaluated.

\section{Materials and methods}

\subsection{Materials}

Sodium alginate (SA) was donated by Alginatos Chile S.A. (Santiago, Chile). Soy lecithin (Epikuron 145V, phosphatidylcholine enriched fraction of soybean lecithin) was supplied by Blumos Ltd (Santiago, Chile). Chia oil (Salvia hispanica L.) was purchased from Natural Oil S.A. (Santiago, Chile). The main fatty acids in the chia oil were C16:0 (7.0 $\pm 2.1 \%), \mathrm{C} 18: 0(3.5 \pm$ $0.1 \%)$, C18:1 $\omega 9(7.9 \pm 0.2 \%)$, C18:2 $\omega 6(19.4 \pm 0.2 \%)$, and C18:3 $\omega 3(65.9 \pm 0.3 \%)$. Peroxide value and induction time of the chia oil were $0.30 \pm 0.05 \mathrm{mEq} \mathrm{O}_{2}$ per $\mathrm{kg}$ and $3.20 \pm 0.05 \mathrm{~h}$, respectively. Aluminum oxide was purchased from Merck (Santiago, Chile). Pepsin from porcine gastric mucosa (P7012, $\left.2500 \mathrm{AU} \mathrm{mg}{ }^{-1}\right)$, pancreatin from porcine pancreas (P7545, $8 \times$ USP specifications), and porcine bile extract (B8631) were purchased from Sigma-Aldrich (Santiago, Chile). Yogurt (FAGE total, $0 \%$ fat, UK) was purchased from a local market.

\subsection{Methods}

2.2.1. Chia oil purification. Chia oil was antioxidantstripped by open column adsorption chromatography $(25 \mathrm{~cm} \times$ $2 \mathrm{~cm})$ packed with activated aluminum oxide $\left(180^{\circ} \mathrm{C}\right.$ for $\left.3 \mathrm{~h}\right)$, according to Yoshida et al. ${ }^{25}$ Purified chia oil (PCO) was analyzed by HPLC to confirm the absence of tocopherols. ${ }^{26}$

2.2.2. Encapsulation of PCO-in-water microemulsions and nanoemulsions. The PCO-in-water microemulsions (ME-PCO) were encapsulated with SA by micro spray-drying, giving the ME-PCO-SA microparticle system. Besides, the PCO-in-water nanoemulsions (NE-PCO) were encapsulated with SA by nano spray-drying, obtaining the NE-PCO-SA nanoparticle system. In both cases, the formulations were performed according to a central composite + star design with 12 runs (4 experimental points, 4 star points, and 4 central points). The independent variables were the inlet air temperature $\left(120-180^{\circ} \mathrm{C}\right.$ for micro spray-drying and $80-110{ }^{\circ} \mathrm{C}$ for nano spray-drying) and the SA content $(0.5-2.0 \mathrm{~g}$ for micro spray-drying and $0.2-0.6 \mathrm{~g}$ for nano spray-drying). The response variable was the encapsulation efficiency (EE) of PCO.

2.2.2.1. Micro spray-drying. The ME-PCO were prepared as follows: PCO $(0.5 \mathrm{~g})$, soy lecithin $(22 \mathrm{mg})$ and distilled water $(20 \mathrm{~g})$ at $40{ }^{\circ} \mathrm{C}$ were stirred using a magnetic stirrer at $500 \mathrm{rpm}$ for $20 \mathrm{~min}$ and then homogenized using a Polytron homogen- 
izer (PT 2100, Kinematica AG, Switzerland) at $19000 \mathrm{rpm}$ for 3 min. SA (0.5-2 g) was dispersed in distilled water (78.98-77.48 g), and stirred in an orbital shaker at $200 \mathrm{rpm}$ (JSSI-100C, JSR, Korea) for 15 min. The ME-PCO were mixed with the SA dispersion and homogenized using a Polytron homogenizer (PT 2100, Kinematica AG, Switzerland) at 19000 $\mathrm{rpm}$ for $3 \mathrm{~min}$. The resulting mixture was fed into a laboratory micro spray-dryer (B-290 mini spray dryer Büchi, co-current form, Switzerland), using a nozzle size of $0.7 \mathrm{~mm}$. The spray dryer was operated with an air inlet temperature ranging from 120 to $180{ }^{\circ} \mathrm{C}$, and with a spray air flow, air flow rate (aspirator) and feed flow rate (peristaltic pump) of $600 \mathrm{~L} \mathrm{~h}^{-1}, 35 \mathrm{~m}^{3} \mathrm{~h}^{-1}$ and $1 \mathrm{~mL} \min ^{-1}$, respectively. The powders were stored in plastic bags at $-18{ }^{\circ} \mathrm{C}$ for further analysis.

2.2.2.2. Nano spray-drying. The NE-PCO were prepared as follows: PCO (0.2 g), soy lecithin $(48 \mathrm{mg})$ and ethanol $(10 \mathrm{~mL})$ were mixed with Milli-Q water $(20 \mathrm{~mL})$. The organic solvent was removed using a rotatory evaporator (R-100 Büchi, Switzerland) and the nanoemulsion was concentrated until $5 \mathrm{~mL}$. The formation of the nanoemulsion was instantaneous and spontaneous, as evidenced by the milky appearance of the mixture and by laser scattering. ${ }^{27}$ The NE-PCO were added to a dispersion of SA (0.2-0.6 g) in water (94.8-94.4 g), and stirred using a magnetic stirrer at $500 \mathrm{rpm}$ for $20 \mathrm{~min}$. The resulting dispersion was fed into a laboratory nano spray-dryer (B-90 mini spray dryer Büchi, co-current form, Switzerland), where a piezoelectric driven actuator performs atomization with a stainless steel membrane of micrometer-sized holes $(7.0 \mu \mathrm{m})$, and the vibration frequency $(60-140 \mathrm{kHz})$ generates a fine and homogeneous spray of droplets. The spray dryer was operated with an air inlet temperature ranging from 80 to $110{ }^{\circ} \mathrm{C}$, and with an air flow and pressure of $120 \mathrm{~mL} \mathrm{~min}{ }^{-1}$ and $30 \mathrm{mbar}$, respectively. The powders were stored in plastic bags at $-18^{\circ} \mathrm{C}$ for further analysis.

2.2.2.3. Statistical design analysis. The response surface methodology (RSM) was applied to determine the optimal conditions for both particle systems (ME-PCO-SA and NE-PCO-SA), maximizing the EE of PCO. Data were fitted to a second order regression model (eqn (1)), where linear, quadratic and crossproduct forms of the inlet air temperature and the SA content were considered.

$$
Y=b_{0}+\sum_{i=1}^{2} b_{i} X_{i}+\sum_{i=1}^{2} b_{i i} X_{i}^{2}+\sum_{i=1}^{1} \sum_{j=i+1}^{2} b_{i j} X_{i} X_{j}+\varepsilon
$$

where $Y$ was the response (EE); subscripts $i$ and $j$ ranged from 1 to the number of variables $(n=2) ; b_{0}$ was the intercept term; $b_{i}$ values were the linear coefficients; $b_{i i}$ values were the quadratic coefficients; $b_{i j}$ values were the cross-product coefficients; $X_{i}$ and $X_{j}$ were the levels of the independent variables; and $\varepsilon$ was the error term. The software Statgraphics (5.0 program, Manugistics Inc., Rockville, MA) was used to perform the analysis of variance (ANOVA), test of lack of fit, and determination of the regression coefficients.

2.2.3. Characterization of the encapsulated chia oil under the optimal conditions. Powder particles (ME-PCO-SA and
NE-PCO-SA) obtained under the optimal conditions were analyzed to determine their water activity $\left(a_{\mathrm{w}}\right)$ by the dew point method using a Hygrolab 2 (Rotronic, USA) at $20 \pm 0.3{ }^{\circ} \mathrm{C}$, moisture content using an infrared moisture analyzer (PMC50, Radwag, USA), and hygroscopicity according to Cai and Corke. $^{28}$

2.2.3.1. Encapsulation efficiency. Surface PCO was determined according to Alcântara et al. ${ }^{10}$ with some modifications. Powder particles (ME-PCO-SA and NE-PCO-SA) (2 g) in hexane $(20 \mathrm{~mL})$ were manually stirred for $1 \mathrm{~min}$ at room temperature and filtered using a Whatman-1 filter. Hexane was removed using a rotatory evaporator (R-100 Büchi, Switzerland) at $40{ }^{\circ} \mathrm{C}$, until constant weight. The encapsulation efficiency was expressed as percentage according to eqn (2).

$$
\mathrm{EE}(\%)=\frac{\text { Total oil }- \text { Surface oil }}{\text { Total oil }} \times 100 .
$$

2.2.3.2. Particle size. Particle size and particle size distribution of ME-PCO-SA and NE-PCO-SA particles obtained under the optimal conditions were analyzed before and after spraydrying by light scattering using a laser diffraction particle size analyzer (Partica LA-960, Horiba, Japan; $650 \mathrm{~nm}$ laser diode). The particles were dispersed in recirculating water, and the particle size was expressed as volume mean diameter $\left(D_{4,3}\right)$.

2.2.4. In vitro gastrointestinal digestion of the ME-PCO-SA and NE-PCO-SA particles. Powder particles obtained under the optimal conditions (ME-PCO-SA and NE-PCO-SA) were subjected to a simulated gastrointestinal digestion according to Brodkorb et al. ${ }^{20}$ with some modifications (no gastric lipase was used, and $\mathrm{pH} 2$ was maintained during the gastric phase). The consecutive conditions of the oral, gastric and intestinal phases were simulated. A sample of ME-PCO-SA and NE-PCO-SA particles (containing $200 \mathrm{mg}$ of PCO) was dispersed in distilled water up to $5 \mathrm{~mL}$. Afterwards, simulated salivary solution $(4 \mathrm{~mL}), 0.3 \mathrm{M} \mathrm{CaCl}_{2}(25 \mu \mathrm{L})$ and distilled water $(0.975 \mathrm{~mL})$ were added to the dispersion. The resulting oral mixture was incubated at $170 \mathrm{rpm}$ and $37^{\circ} \mathrm{C}$ for $2 \mathrm{~min}$ in an orbital shaker (JSSI-100, JSR, Korea). Subsequently, the oral bolus $(10 \mathrm{~mL})$ was mixed with the simulated gastric solution $(8 \mathrm{~mL}), 0.3 \mathrm{M} \mathrm{CaCl}_{2}(5 \mu \mathrm{L})$, pepsin $\left(2000 \mathrm{U} \mathrm{mL}^{-1}\right.$ of the gastric phase) and $\mathrm{HCl}(0.5 \mathrm{M})$ to adjust the $\mathrm{pH}$ to 2 and water up to $20 \mathrm{~mL}$. The total mixture was incubated at $170 \mathrm{rpm}$ and $37^{\circ} \mathrm{C}$ for 120 minutes. Finally, the gastric bolus $(20 \mathrm{~mL})$ was mixed with the simulated intestinal solution (16 mL), $0.3 \mathrm{M} \mathrm{CaCl}_{2}$ $(40 \mu \mathrm{L})$ and $\mathrm{NaOH}(1 \mathrm{M})$ to adjust the $\mathrm{pH}$ to 7.0 , the bile extract (10 mM), and pancreatin (lipase activity of $2000 \mathrm{U} \mathrm{mL}^{-1}$ of the intestinal phase). A pH-stat (902 Titrando, Metrohm, Switzerland) was used to maintain the $\mathrm{pH}$ at 7.00 for $2 \mathrm{~h}$ at $37{ }^{\circ} \mathrm{C}$ by adding $\mathrm{NaOH}(1 \mathrm{M})$ under continuous agitation. At the end of the digestion, lipases were inactivated by adding bromophenylboronic acid ( $5 \mathrm{mM})$. The digested samples were collected and stored at $-80^{\circ} \mathrm{C}$ until analysis.

2.2.4.1. Determination of the $P C O$ released from the $M E-P C O-S A$ and NE-PCO-SA particles during in vitro gastrointestinal digestion. The PCO released from ME-PCO-SA and NE-PCO-SA particles after every digestion phase (oral, gastric 
and intestinal) was determined according to Yang and Ciftci, ${ }^{29}$ with some modifications. A mixture of hexane:methanol $(1: 1, v / v)$ was added to the digested sample from every phase ( $1: 3$ digested sample: solvent mixture, v/v) at $\mathrm{pH} 5$ (adjusted with $\mathrm{HCl} 0.5 \mathrm{M}$ ), stirred for $1 \mathrm{~min}$ and centrifuged at $3000 \mathrm{~g}$ for $4 \mathrm{~min}$. The supernatant (hexane fraction) was withdrawn and the extraction was repeated three times. The supernatants were combined and hexane was removed using an evaporating system (Genevac EZ-2 Plus, UK) at $40{ }^{\circ} \mathrm{C}$. The residual solvent was removed using a stream of nitrogen to obtain the PCO released. Furthermore, the PCO release after every digestion phase of ME-PCO microemulsions and NE-PCO nanoemulsions was also determined for comparative purposes.

2.2.4.2. Bioaccessibility of individual FFA from the digested $M E-P C O-S A$ and NE-PCO-SA particles. The extraction of free fatty acids (FFA) released during the intestinal digestion was performed according to $\mathrm{Ng}$ et al. ${ }^{30}$ Briefly, the $\mathrm{pH}$ of an aliquot of the digested sample $(4 \mathrm{~mL})$ was adjusted to 10 with $\mathrm{NaOH}$ (10 M). Then, the triacylglycerides were extracted with dichloromethane $(6 \mathrm{~mL})$, stirring at $20{ }^{\circ} \mathrm{C}$ and $170 \mathrm{rpm}$ for $24 \mathrm{~h}$ using an orbital shaker (JSSI-100, JSR, Korea). The organic phase was removed, and the $\mathrm{pH}$ of the aqueous phase was adjusted to 1-2 with $\mathrm{HCl}(1 \mathrm{M})$. Finally, the FFA were extracted with dichloromethane $(4 \mathrm{~mL})$, stirring at $20^{\circ} \mathrm{C}$ and $170 \mathrm{rpm}$ for $24 \mathrm{~h}$ using the orbital shaker. An aliquot of the dichloromethane layer $(1 \mathrm{~mL})$ was methylated and analyzed by gas chromatography. Fatty acid methyl esters were prepared by methylation using $\mathrm{H}_{2} \mathrm{~S}_{2} \mathrm{O}_{4}$ in methanol $(0.06 \%$, v/v). Fatty acid methyl esters were analyzed using a gas chromatograph (7890B, Agilent Technologies, USA), equipped with a flame ionization detector (FID) and HP-88 column (fused-silica capillary column $0.25 \mathrm{~mm}$ i.d., $0.20 \mu \mathrm{m}$ film thickness, $100 \mathrm{~m}$, Agilent Technologies, USA). Injector and detector temperatures were set at $250{ }^{\circ} \mathrm{C}$. The oven temperature was programmed at $180{ }^{\circ} \mathrm{C}$ for $32 \mathrm{~min}$, increasing to $230{ }^{\circ} \mathrm{C}$ at $20^{\circ} \mathrm{C} \mathrm{min}^{-1}$, and held for $32 \mathrm{~min}$. The individual fatty acids were identified and quantified using a calibration curve obtained with fatty acid methyl esters as external standards (C16:0, 0.05-2.58 mg $\mathrm{mL}^{-1}$; C18:0, 0.01-1.0 mg mL $\mathrm{mL}^{-1}$ C18:1, 0.02-8.48 $\mathrm{mg} \mathrm{mL}^{-1}$; C18:2, 0.01-8.48 $\mathrm{mg} \mathrm{mL}^{-1}$; C18:3, 0.01-18.22 $\mathrm{mg} \mathrm{mL}^{-1} ; R^{2}>$ 0.99 in all of them).

The bioaccessibility of every major fatty acid of CO was calculated according to eqn (3).

$$
\text { Bioaccesibility }=\frac{\mathrm{mg} \text { of FFA after digestion }}{\mathrm{mg} \text { of encapsulated fatty acids }} \times 100
$$

\subsubsection{Incorporation of the ME-PCO-SA and NE-PCO-SA par- ticles into yogurt}

2.2.5.1. Release of the PCO in yogurt. Cellulose filter bags containing the ME-PCO-SA and NE-PCO-SA particles (weight corresponding to $200 \mathrm{mg}$ PCO) were placed into bottles containing $5 \mathrm{~g}$ of yogurt ( $0 \% \mathrm{fat}$ ) and stored in a shaker incubator (JSSI-100, JSR, Korea) at $5{ }^{\circ} \mathrm{C}$ and $170 \mathrm{rpm}$. Samples were collected at specific time intervals during storage and the PCO release was determined as described in section 2.2.4.1.
Furthermore, the release of the PCO from the ME-PCO microemulsions and NE-PCO nanoemulsions was also determined for comparative purposes.

2.2.5.2. In vitro gastrointestinal digestion of yogurt containing the ME-PCO-SA and NE-PCO-SA particles. A sample of ME-PCO-SA and NE-PCO-SA particles (containing $200 \mathrm{mg}$ of the PCO) was incorporated into yogurt ( $5 \mathrm{~g}$ ) and subjected to a simulated gastrointestinal digestion according to Brodkorb et al. ${ }^{20}$ as described in section 2.2.4. Yogurt containing the ME-PCO microemulsions and NE-PCO nanoemulsions was also subjected to gastrointestinal digestion for comparative purposes.

2.2.5.1. Determination of the PCO released during the in vitro gastrointestinal digestion of yogurt

The PCO released after every digestion phase (oral, gastric and intestinal) of yogurt containing particles (ME-PCO-SA or NE-PCO-SA) and emulsions (ME-PCO and NE-PCO) was determined according to section 2.2.4.1.

2.2.6. Statistical analyses. All the experiments were performed in triplicate. Analysis of variance (ANOVA) and Tukey's multiple range test were applied to determine the statistical differences among samples, using Statgraphics Centurion XVI software (Statistical Graphics Corporation, USA).

\section{Results and discussion}

\subsection{Encapsulation of the PCO by micro and nano spray- drying}

The purification process of chia oil, which had no significant effect on the fatty acid profile, was verified by the absence of tocopherols in the PCO (ESI 1†). The ME-PCO-SA and NE-PCO-SA particles were prepared by applying a central composite plus star design. Table 1 shows the experimental conditions and response variable for the microencapsulation of the PCO. As spray-drying is more a method of immobilization than true encapsulation, the EE of the PCO was evaluated as a response variable. ${ }^{31} \mathrm{~A}$ higher $\mathrm{EE}$ of the PCO represents a higher amount of the PCO within the particles, whereas the PCO on the surface of the particles remains exposed to environmental conditions and therefore it is susceptible to oxidative degradation. The EE of the PCO ranged from 74.9 to 91.9\% for ME-PCO-SA and 81.2 to $98.5 \%$ for NE-PCO-SA, within the range of EE reported for the encapsulated oils rich in polyunsaturated fatty acids by spray-drying (26-99\%). ${ }^{3,32}$

The linear $(p<0.05)$ and quadratic forms $(p<0.05)$ of the SA content and the inlet air temperature had a significant influence on the EE of the PCO for both ME-PCO-SA and NE-PCO-SA particle systems (Table 2). According to the analyses of variance, the model explained $99.5 \%$ and $99.4 \%$ of the variability for the ME-PCO-SA and NE-PCO-SA, respectively. Moreover, the lack of fit was not significant and the residual values were below 1 in both cases, indicating that the mathematical model fit well to the experimental data.

Although the experimental domains under study for the SA content and the inlet air temperature were different in the 
Table 1 Experimental design for the encapsulation of ME-PCO microemulsion and NE-PCO nanoemulsion with SA by spray-drying

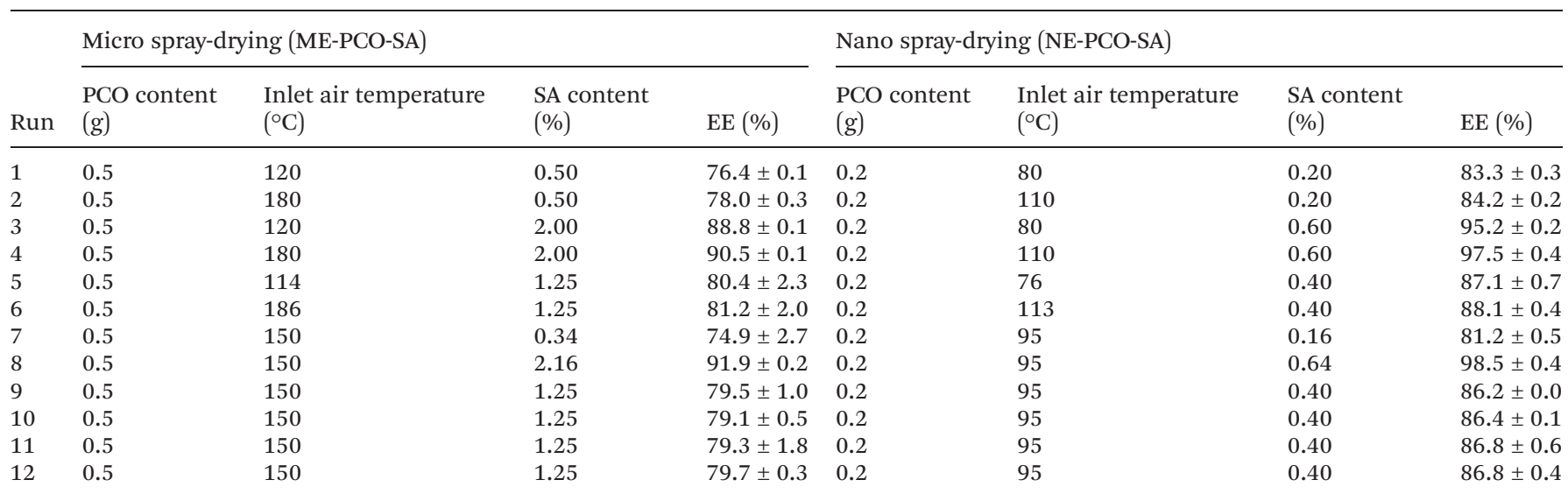

PCO: purified chia oil; SA: sodium alginate; EE: encapsulation efficiency; ME-PCO-SA: PCO-in-water microemulsion encapsulated with SA by micro spray-drying; NE-PCO-SA: PCO-in-water nanoemulsion encapsulated with SA by nano spray-drying.

Table 2 ANOVA for the encapsulation of ME-PCO and NE-PCO with SA by spray-drying

\begin{tabular}{|c|c|c|c|c|}
\hline & \multicolumn{2}{|c|}{ ME-PCO-SA } & \multicolumn{2}{|c|}{ NE-PCO-SA } \\
\hline & Estimate & $p$-Value & Estimate & $p$-Value \\
\hline$\beta o$ & 100.523 & & 116.119 & \\
\hline$X_{1}$ & -0.3425 & 0.0082 & -0.7393 & 0.0113 \\
\hline$X_{2}$ & -3.9819 & 0.0000 & -15.9565 & 0.0000 \\
\hline$X_{1}^{2}$ & 0.0012 & 0.0032 & 0.0041 & 0.0078 \\
\hline$X_{2}^{2}$ & 5.0930 & 0.0002 & 61.5627 & 0.0004 \\
\hline$X_{1} X_{2}$ & & $0.8588^{a}$ & & $0.1018^{\circ}$ \\
\hline Lack of fit & & 0.0832 & & 0.0783 \\
\hline$R^{2}$ (adj. d.f.) & & 99.15 & & 98.80 \\
\hline
\end{tabular}

$X_{1}$ : inlet air temperature; $X_{2}$ : sodium alginate content; ME-PCO-SA: PCO-in-water microemulsion encapsulated with SA by micro spraydrying; NE-PCO-SA: PCO-in-water nanoemulsion encapsulated with SA by nano spray-drying; adj. d.f.: adjusted for the degrees of freedom. ${ }^{a}$ Interaction was excluded $(p>0.05)$.

ME-PCO-SA and NE-PCO-SA experimental designs (Table 1), the response surface graphs (Fig. 1) showed that when the SA content increased in both the systems and the inlet air temperature was above $150{ }^{\circ} \mathrm{C}$ in the ME-PCO-SA (Fig. 1a) and $100{ }^{\circ} \mathrm{C}$ in the NE-PCO-SA (Fig. 1b), the EE of the PCO increased, although the effect of the SA content was more noticeable than that of the inlet air temperature. Thus, higher solid contents and inlet air temperatures increase the crust formation rate over the oil droplets, allowing the diffusion of water, retaining the PCO and therefore increasing the EE. ${ }^{33}$ Maximizing the EE, the optimal conditions for the SA content and the inlet air temperature in the ME-PCO-SA $(2.15 \%$ and $186{ }^{\circ} \mathrm{C}$, respectively) and NE-PCO-SA (0.64\% and $113{ }^{\circ} \mathrm{C}$, respectively) were close to the star points. These drying conditions were in the range reported in the literature for the encapsulation of polyunsaturated oils (inlet air temperature: $90-225{ }^{\circ} \mathrm{C}$; oil : encapsulating agent ratios: $1: 1-1: 10) \cdot{ }^{34-36}$
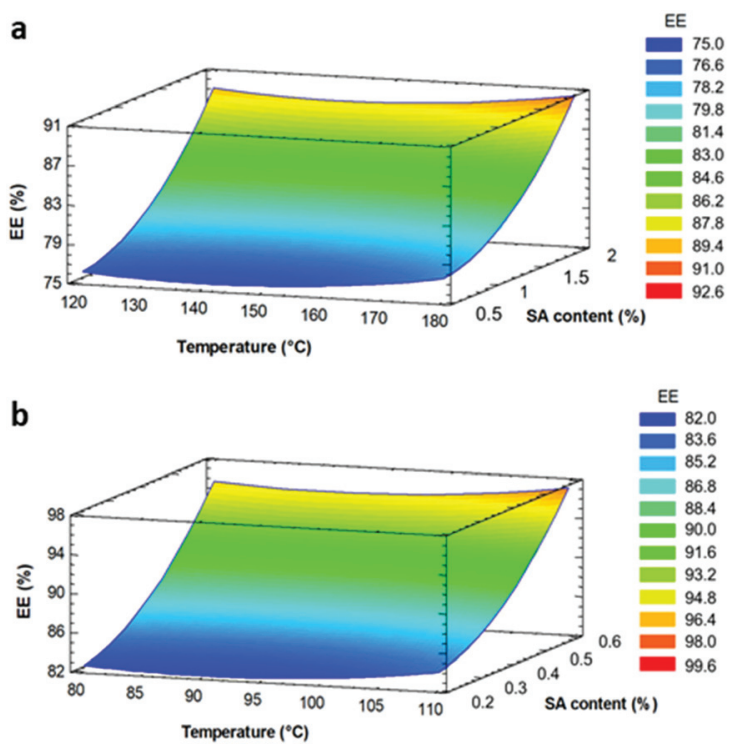

Fig. 1 Response surface graphics for determining the encapsulation efficiency (EE) of PCO encapsulation by spray-drying. (a) PCO microencapsulation (ME-PCO-SA) and (b) PCO nanoencapsulation (NE-PCO-SA).

\subsection{Characterization of the ME-PCO-SA and NE-PCO-SA microparticles obtained under the optimal conditions}

Table 3 shows the optimal conditions and physicochemical characterization of the ME-PCO-SA and NE-PCO-SA, obtained by micro and nano spray-drying, respectively. Before spraydrying, the PCO-in-water nanoemulsion (ME-PCO) showed a droplet size of $0.13 \pm 0.01 \mu \mathrm{m}$, whereas the PCO-in-water microemulsion (NE-PCO) reached a droplet size of $3.20 \pm 0.30 \mu \mathrm{m}$ (Table 3). After spray-drying, the particle size reached values of $0.16 \pm 0.02 \mu \mathrm{m}$ for the NE-PCO-SA and $3.50 \pm 0.14 \mu \mathrm{m}$ for the ME-PCO-SA, showing that the emulsion preparation method, the drying method and the SA content influenced the powder particle size. ${ }^{37}$ 
Table 3 Characterization of the ME-PCO-SA and NE-PCO-SA particle systems obtained under the optimal conditions

\begin{tabular}{lll}
\hline & ME-PCO-SA & NE-PCO-SA \\
\hline SA content $(\%)$ & 2.16 & 0.64 \\
Inlet air temperature $\left({ }^{\circ} \mathrm{C}\right)$ & 186 & 113 \\
Droplet size $(\mu \mathrm{m})$ & $3.20 \pm 0.30^{\mathrm{a}}$ & $0.13 \pm 0.01^{\mathrm{b}}$ \\
Oil content $\left(\mathrm{mg} \mathrm{PCO} \mathrm{g}{ }^{-1}\right.$ powder$)$ & $187.2 \pm 0.1^{\mathrm{a}}$ & $235.2 \pm 0.2^{\mathrm{b}}$ \\
EE $(\%)$ & $92.0 \pm 2.1^{\mathrm{a}}$ & $98.1 \pm 1.2^{\mathrm{b}}$ \\
Moisture content $(\%)$ & $7.2 \pm 1.5^{\mathrm{a}}$ & $7.9 \pm 1.2^{\mathrm{a}}$ \\
$a_{\mathrm{w}}$ & $0.154 \pm 0.002^{\mathrm{a}}$ & $0.204 \pm 0.001^{\mathrm{b}}$ \\
Hygroscopicity $(\%)$ & $55.2 \pm 1.10^{\mathrm{b}}$ & $46.1 \pm 2.50^{\mathrm{a}}$ \\
Particle size $(\mu \mathrm{m})$ & $3.50 \pm 0.14^{\mathrm{b}}$ & $0.16 \pm 0.02^{\mathrm{a}}$
\end{tabular}

PCO: purified chia oil; SA: sodium alginate; EE: encapsulation efficiency; $a_{\mathrm{w}}$ : water activity. Different letters show significant differences $(p<0.05)$ between the particle systems.

The EE represents the retention of the PCO-in-water emulsion within the particles, ideally a minimum oil content on the surface of the particle. The inlet air temperature and the solid content are variables studied to maximize the EE of the PCO by spray-drying, as was described above. Another parameter affecting the oil EE is the droplet size of the emulsions. Smaller droplet sizes in oil-in-water emulsions have been associated with higher $\mathrm{EE}^{10}$ in agreement with this study where significantly $(p<0.05)$ higher $\mathrm{EE}$ was found in the NE-PCO-SA (98.1\%) than in the ME-PCO-SA (92.0\%). Similarly, the smallest droplet size of the chia oil-in-water emulsion using ultrasound as the homogenization method achieved a high EE of chia oil (95.93\%) in the microparticles with a blend of maltodextrin (10 and 20 dextrose equivalent), whey protein isolate and Arabic gum by spray-drying. ${ }^{10}$ The EE values obtained in this study ( $>90 \%$ ) were similar to those obtained using other biopolymers, such as sodium caseinate + lactose $(95.2 \%)$, sodium caseinate + lactose + mucilage $(96.23 \%),{ }^{12}$ whey protein concentrate/Hi-Cap ${ }^{\circledR}(99.74 \%)$ and whey protein concentrate/pectin/maltodextrin (10 dextrose equivalent) (99.95\%) based on electrostatic layer-by-layer deposition. ${ }^{15}$ However, lower values of EE for chia oil have been reported using whey protein concentrate + mesquite gum or Arabic gum $(70.7-80.7 \%),{ }^{17}$ soy protein isolate, and soy protein isolate + maltodextrin (52.5-60.2\%), ${ }^{13}$ indicating that the type of encapsulation agent is one of the factors influencing the EE, together with the processing conditions (inlet and outlet air temperatures and infeed temperature), the emulsification process and the characteristics of the prepared emulsion (droplet size and emulsion stability). ${ }^{38}$

The moisture content was similar between the ME-PCO-SA (7.2\%) and NE-PCO-SA (7.9\%). However, these values were higher than the moisture range (3-4\%) specified for powdered ingredients in the food industry. ${ }^{39}$ The $a_{\mathrm{w}}$ was significantly lower $(p<0.05)$ in the ME-PCO-SA (0.154) than in the NE-PCO-SA (0.223), but both $a_{\mathrm{w}}$ values indicate a low risk of microbial spoilage. ${ }^{40}$ The water activity influences the physical changes of the chia oil microparticle powders and the oil stability during storage. Escalona-García et al. ${ }^{14}$ studied the variation in the glass transition temperature $\left(T_{\mathrm{g}}\right)$ at a given $a_{\mathrm{w}}$
(0.108-0.821) in chia oil encapsulated with whey protein concentrate + mesquite gum and stored at $35{ }^{\circ} \mathrm{C}$. They reported that the $\mathrm{Tg}$ decreased with increasing $a_{\mathrm{w}}$ due to a plasticizer effect, depending on the storage temperature and the biopolymer properties. Moreover, the hygroscopicity was significantly lower in the NE-PCO-SA $(46.1 \%)$ than in the ME-PCO-SA (55.2\%). Similarly, Santos Fernandes et al. ${ }^{8}$ reported that smaller-sized chia oil microparticles with maltodextrin + Arabic gum showed lower hygroscopicity, which can be explained by a reduction in the spaces between the particles, decreasing both water penetration and hygroscopicity. The ME-PCO-SA system showed lower $a_{\mathrm{w}}$ values but more hygroscopic particles. This result was similar to those obtained by Vélez-Erazo et al., ${ }^{9}$ where microencapsulated chia oil with pea protein/maltodextrin $\left(a_{\mathrm{w}}: 0.114\right)$ was more hygroscopic than pea protein/Hi-Cap ${ }^{\circledR} 100\left(a_{\mathrm{w}}: 0.150\right)$.

\subsection{In vitro gastrointestinal digestion of the ME-PCO-SA and NE-PCO-SA particles}

3.3.1. PCO released from the ME-PCO-SA and NE-PCO-SA particles during in vitro gastrointestinal digestion. Table 4 shows the amount of the PCO released from the particle systems (ME-PCO-SA and NE-PCO-SA) and the emulsion systems (ME-PCO and NE-PCO) after every phase of the gastrointestinal digestion, as well as the total percentage of the PCO released at the end of the digestion. Both ME-PCO and NE-PCO emulsions showed a sustained oil release throughout the three phases of digestion, with a greater release during the oral phase, whereas the oil release from the ME-PCO-SA and NE-PCO-SA particles mainly occurred during the intestinal phase, showing the effect of SA as an intestine-site delivery polymer. ${ }^{41}$ This polymer $\left(\mathrm{p} K_{\mathrm{a}}: 3.2\right)$ is insoluble under gastric conditions, while it swells and disintegrates in alkaline medium, such as the intestinal environment ( $\mathrm{pH}$ above 6), facilitating the release of the encapsulated lipids. This $\mathrm{pH}$-sensitive behavior of SA is the reason why it is widely used in the

Table 4 PCO released from the particles (NE-PCO-SA and ME-PCO-SA) and emulsions (ME-PCO and NE-PCO) in the different phases of the in vitro gastrointestinal digestion, both alone and when incorporated into yogurt

\begin{tabular}{llll}
\hline PCO in & PCO in & PCO in & Total \\
OP (mg) & OP + GP (mg) & OP + GP + IP (mg) & PCO (\%) \\
\hline
\end{tabular}

System digestion

ME-PCO-SA $10.2 \pm 0.3^{\mathrm{a}}$ nd

NE-PCO-SA $17.0 \pm 2.3^{\mathrm{b}}$ nd

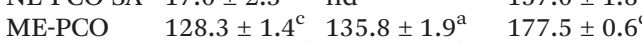

NE-PCO $\quad 142.9 \pm 1.3^{\mathrm{d}} \quad 156.8 \pm 3.3^{\mathrm{b}} \quad 178.5 \pm 2.1^{\mathrm{c}}$

$69.8 \pm 2.3^{\mathrm{a}}$

Yogurt digestion

ME-PCO-SA nd

$\begin{array}{lll}\text { NE-PCO-SA } & \text { nd } & \text { nd } \\ \text { ME-PCO } & 82.0 \pm 3.1^{\mathrm{b}} & 86.5 \pm 2.4^{\mathrm{b}} \\ \text { NE-PCO } & 80.6 \pm 2.8^{\mathrm{b}} & 84.8 \pm 1.9^{\mathrm{b}}\end{array}$

$123.5 \pm 0.7^{\mathrm{a}}$

$117.5 \pm 2.1^{\mathrm{a}}$

$162.5 \pm 2.1^{\mathrm{b}}$

$159.1 \pm 3.2^{\mathrm{b}}$

$78.4 \pm 0.9^{\mathrm{b}}$

$88.8 \pm 0.3^{\mathrm{c}}$

$89.3 \pm 1.1^{\mathrm{c}}$

$61.8 \pm 0.3^{\mathrm{a}}$ $58.8 \pm 1.1^{\mathrm{a}}$ $81.2 \pm 1.1^{\mathrm{b}}$ $80.0 \pm 2.1^{\mathrm{b}}$

PCO: purified chia oil; SA: sodium alginate; OP: oral phase; GP: gastric phase; IP: intestinal phase. Different letters in the same column indicate significant differences $(p<0.05)$ among the systems. nd: nondetected. 
pharmaceutical industry for the controlled release of bioactive compounds.

Moreover, the amount of the PCO released from the NE-PCO-SA (157 mg) was significantly higher than that released from the ME-PCO-SA particles (139 mg; Table 3), showing an effect of the particle size on the PCO release where smaller-sized particles have a greater surface area exposed to the intestinal environment, leading to higher disintegration of SA and PCO release. Similarly, the total percentage of oil released was higher in the NE-PCO-SA (78.4\%) than in the ME-PCO-SA (69.8\%). These values were higher than those reported in other studies for microencapsulated chia oil. Timilsena et al. $^{21}$ encapsulated chia oil with chia seed protein isolate (CPI) or chia seed gum (CSG) and CPI-CSG, studying the influence of the encapsulating material on the oil release and lipolysis. The oil release was higher in the gastric phase (38-84\%) than in the intestinal phase (15-23\%). In the case of chia oil encapsulated with whey protein, ${ }^{11}$ the oil release reached $8.24 \%$ under the simulated gastric conditions and $21.32 \%$ at the end of the simulated gastrointestinal digestion.

3.3.2. Bioaccessibility of individual FFA from the digested ME-PCO-SA and NE-PCO-SA particles. The bioaccessibility of the major individual free fatty acids from the digested ME-PCO-SA and NE-PCO-SA is shown in Fig. 2.

TAG lipolysis occurs mainly during intestinal digestion, where both $s n-1$ and $s n-3$ ester bonds are cleaved by the pancreatic lipase, giving 2-monoacylglycerides and FFA as lipolytic metabolites. ${ }^{42}$ The bioaccessibility of all the FFA was higher in the NE-PCO-SA than in the ME-PCO-SA (Fig. 2), due to both the higher PCO release and the higher surface area exposed to pancreatic lipases during digestion, similar to that reported for the oil-in-water emulsions subjected to in vitro gastrointestinal digestion. ${ }^{23,43}$ In this study, the chain length and the degree of unsaturation of the FFA influenced their bioaccessibility. Thus, the bioaccessibility of the FFA tended to increase with decreasing both the chain length and the degree of unsaturation in both NE-PCO-SA and ME-PCO-SA. In this context, Ye et $a{ }^{44}{ }^{44}$ reported that the position of fatty acids in the TAG structures, fatty acid chain length, and degree of unsaturation of the fatty acids influence the extent of TAG lipolysis.

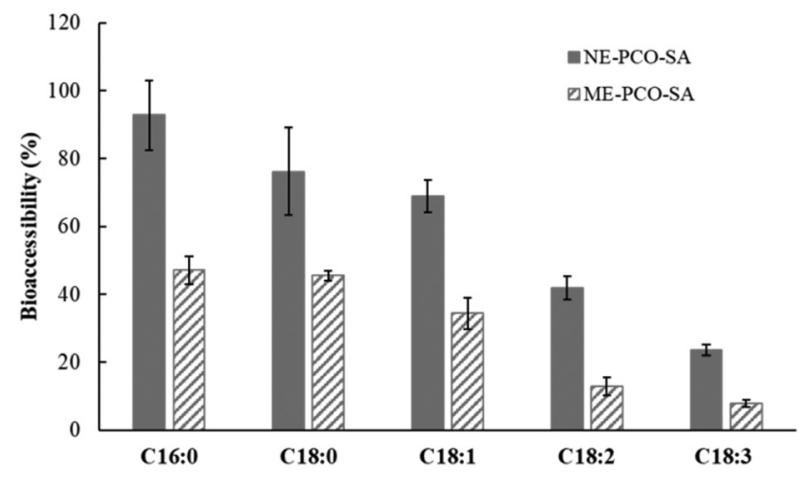

Fig. 2 Bioaccessibility of FFA at the end of the in vitro gastrointestinal digestion of the ME-PCO-SA and NE-PCO-SA particle systems.

\subsection{Incorporation of the ME-PCO-SA and NE-PCO-SA particles} into yogurt

3.4.1. Release of the PCO in yogurt. Fig. 3 shows the release profile of the PCO from the ME-PCO-SA and NE-PCO-SA particles as well as the ME-PCO and NE-PCO emulsions in yogurt stored for 9 weeks at $5{ }^{\circ} \mathrm{C}$. The NE-PCO nanoemulsions showed a significantly higher PCO release $(\sim 8 \%)$ in yogurt compared to the ME-PCO microemulsions, since NE-PCO have a greater contact surface area with yogurt than the microemulsions. A lower release of the PCO in yogurt was found from the ME-PCO-SA and NE-PCO-SA particles when SA was used as an encapsulating agent, which could be explained because $\mathrm{SA}$ is insoluble in aqueous systems at $\mathrm{pH}$ lower than 5 , such as yogurt ( $\mathrm{pH} 3-4)$. The PCO released form the ME-PCO-SA $(4.53 \pm 0.04 \%)$ particles can be attributed to the release of the superficial PCO (non-encapsulated) (8\%), whereas in the case of NE-PCO-SA, the PCO released (10.04 \pm $0.01 \%$ ) corresponds to both the superficial PCO (1.9\%) and encapsulated PCO, showing that the greater surface area of these nanoparticles promotes the PCO release in yogurt.

3.4.2. Determination of the PCO released during the in vitro gastrointestinal digestion of yogurt. Table 4 shows the PCO released after every phase of digestion (oral, gastric and intestinal) of yogurt containing particles (ME-PCO-SA and NE-PCO-SA) and emulsions (ME-PCO and NE-PCO). Although PCO was released in every digestion phase of the yogurt in the case of the emulsion systems, this was mainly released in the oral ( $\sim 80 \mathrm{mg}$ ) and intestinal phases ( $\sim 5 \mathrm{mg})$, with a low release in the gastric phase $(\sim 4 \mathrm{mg})$. In contrast, PCO was neither detected in the oral phase nor in the gastric phase of digestion of yogurt containing particles (ME-PCO-SA and NE-PCO-SA), and the oil was only released during the intestinal phase, showing again the suitability of SA as an intestine-site delivery polymer. ${ }^{41}$ Furthermore, although the total PCO released from the ME-PCO and NE-PCO emulsions at the end of yogurt digestion was significantly higher $(81.2 \%$ and $80.0 \%$, respectively) than that released from the particle systems (61.8\% ME-PCO-SA; 58.8\% NE-PCO-SA), the latter allowed a

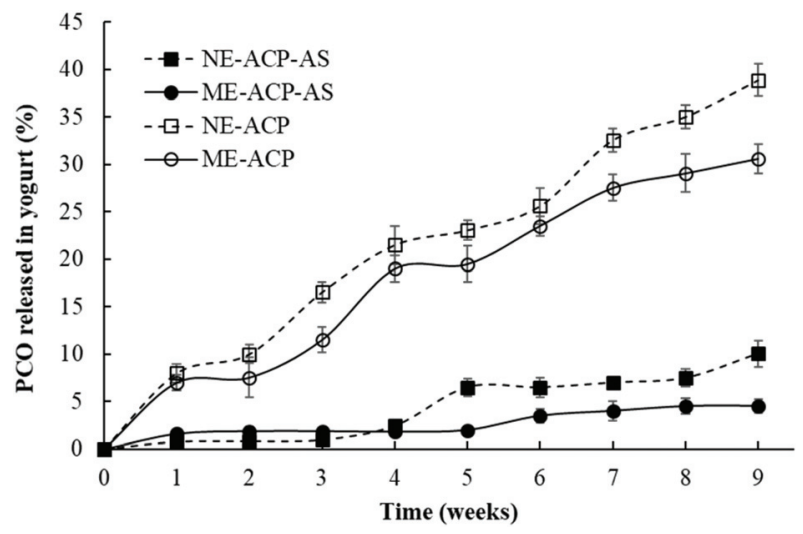

Fig. 3 Release profile of the PCO from the particles (ME-PCO-SA and NE-PCO-SA) and emulsions (ME-PCO and NE-PCO) in yogurt. 
higher release of the PCO during the intestinal phase where lipids were absorbed. The incorporation of both emulsion and particle systems into a food matrix, such as yogurt, led to a lower release of the PCO from all the delivery systems during digestion, as can be concluded by comparing the total PCO (Table 4). This decrease in the PCO release during digestion due to their incorporation into yogurt was more noticeable in the case of the NE-PCO-SA particles (NE-PCO-SA, 78.4\%; NE-PCO-SA in yogurt, 58.8\%). When oil droplets are dispersed in a solid-like food matrix such as yogurt, the structure of the surrounding food matrix may impair the diffusion of the enzymes towards the surface of the dispersed oil droplets. ${ }^{45}$ Furthermore, in the case of the particle systems, and especially in the NE-PCO-SA nanoparticles with a greater surface area, calcium contained in the yogurt may induce partial ionic gelation of SA, forming a shell around the particles that impairs the PCO release. Several food matrices have been functionalized with chia oil encapsulated by spray-drying, such as cookies, butter, burgers and pasta, ${ }^{46-49}$ but the role of chia oil spray-dried microparticles as a delivery system of chia oil during digestion has not been addressed.

\section{Conclusions}

The greater surface area of the nano-sized particles (NE-PCO-SA) allowed a higher EE of the PCO, as well as a higher release of the PCO and bioaccessibility of the FFA during in vitro gastrointestinal digestion, showing the key role of the particle size on the encapsulation parameters and the performance of the delivery systems during gastrointestinal digestion. When yogurt containing particles was subjected to digestion, the release of the PCO was still high $(>58 \%)$. The food matrix reduced the PCO released from both micro- and nano-sized particles, suggesting that the diffusion of the enzymes towards the surface of the dispersed oil droplets was impaired by the surrounding food matrix. Furthermore, microand nano-sized particles were able to preserve the PCO during the storage of yogurt, showing a low release. Therefore, SA spray-dried micro and nanoparticles, especially the latter, showed great potential for vehiculation of omega-3 rich oils in the design of functional foods, allowing the preservation of their nutritional properties in the food matrix and their intestine-site release.

\section{Conflicts of interest}

There are no conflicts to declare.

\section{Acknowledgements}

This research was funded by ANID (Fondecyt Project 1181329; National PhD Scholarship 21160009), Chile.

\section{References}

1 K. E. Lane, M. Wilson, T. G. Hellon and I. G. Davies, Bioavailability and conversion of plant based sources of omega-3 fatty acids - a scoping review to update supplementation options for vegetarians and vegans, Crit. Rev. Food Sci. Nutr., 2021, 12, 1-16.

2 K. B. Kim, Y. A. Nam, H. S. Kim, A. W. Hayes and B. M. Lee, $\alpha$-Linolenic acid: Nutraceutical, pharmacological and toxicological evaluation, Food Chem. Toxicol., 2014, 70, 163178.

3 A. M. Bakry, S. Abbas, B. Ali, H. Majeed, M. Y. Abouelwafa, A. Mousa and L. Liang, Microencapsulation of oils: a comprehensive review of benefits, techniques, and applications, Compr. Rev. Food Sci. Food Saf., 2016, 15, 143-182.

4 J. C. Ruiz Ruiz, E. L. Ortiz Vazquez and M. R. Segura Campos, Encapsulation of vegetable oils as source of omega-3 fatty acids for enriched functional foods, Crit. Rev. Food Sci. Nutr., 2017, 57, 1423-1434.

5 K. Desai and H. Park, Developments in microencapsulation of food ingredients, Drying Technol., 2005, 23, 1361-1294.

6 M. G. Bordón, N. P. X. Alasino, V. Martínez, R. Gauna Peter, R. Iturralde, P. D. Ribotta and M. L. Martínez, Influence of the spray-drying operating conditions on the estimated drying kinetics of emulsion single droplets and the properties of microencapsulated chia oil, Powder Technol., 2021, 383, 302-317.

7 N. Castejón, P. Luna and F. J. Señoráns, Microencapsulation by spray-drying of omega-3 lipids extracted from oilseeds and microalgae: Effect on polyunsaturated fatty acid composition, LWT - Food Sci. Technol., 2021, 148, 111789.

8 S. Santos Fernandes, L. Greque, M. F. Santos, L. M. R. Novais, C. Montes D'Oca, C. Prentice and M. M. Salas-Mellado, Effect of the spray-drying conditions on the physicochemical and structural characteristics and the stability of chia oil microparticles, J. Appl. Polym. Sci., 2021, 138, e51015.

9 E. M. Vélez-Erazo, I. L. Silva, T. Comunian, L. E. Kurozawa and M. Dupas Hubinger, Effect of chia oil and pea protein content on stability of emulsions obtained by ultrasound and powder production by spray-drying, J. Food Sci. Technol., 2021, 58, 3765-3779.

10 M. A. Alcântara, A. E. Alcântara, A. de Lima, L. Mattos Braga, R. V. Tonon, M. C. Galdeano, M. da Costa Mattos, A. I. Santa Brígida, R. Rosenhaim, N. Albuquerque dos Santos and A. M. Tribuzy de Magalhães Cordeiro, Influence of the emulsion homogenization method on the stability of chia oil microencapsulated by spray-drying, Powder Technol., 2019, 354, 877-885.

11 M. Lavanya, T. Kathiravan, J. A. Moses and C. Anandharamakrishnan, Influence of spray-drying conditions on microencapsulation of fish oil and chia oil, Drying Technol., 2019, 38, 1-14.

12 U. Us-Medina, L. M. Julio, M. R. Segura-Campos, V. Y. Ixtaina and M. C. Tomás, Development and character- 
ization of spray-dried chia oil microparticles using byproducts from chia as wall material, Powder Technol., 2018, 334, 1-8.

13 A. González, M. L. Martínez, A. J. Paredes and A. E. León, Study of the preparation process and variation of wall components in chia (Salvia hispanica L.) oil microencapsulation, Powder Technol., 2016, 301, 868-875.

14 L. A. Escalona-García, R. Pedroza-Islas, R. Natividad, M. E. Rodríguez-Huezo, H. Carrillo-Navas and C. PerezAlonso, Oxidation kinetics and thermodynamic analysis of chia oil microencapsulated in a whey protein concentratepolysaccharide matrix, J. Food Eng., 2016, 175, 93-103.

15 C. Noello, A. G. S. Carvalho, V. M. Silva and M. D. Hubinger, Spray dried microparticles of chia oil using emulsion stabilized by whey protein concentrate and pectin by electrostatic deposition, Food Res. Int., 2016, 89, 549-557.

16 V. Y. Ixtaina, L. M. Julio, J. R. Wagner, S. M. Nolasco and M. C. Tomás, Physicochemical characterization and stability of chia oil microencapsulated with sodium caseinate and lactose by spray-drying, Powder Technol., 2015, 271, 2634.

17 D. A. Rodea-González, J. Cruz-Olivares, A. Román-Guerrero, M. E. Rodríguez-Huezo, E. J. Vernon-Carter and C. PérezAlonso, Spray-dried encapsulation of chia essential oil (Salvia hispanica L.) in whey protein concentrate-polysaccharide matrices, J. Food Eng., 2012, 111, 102-109.

18 L. de Souza Simões, D. A. Madalena, A. C. Pinheiro, J. A. Teixeira, A. A. Vicente and Ó. L. Ramos, Micro- and nano bio-based delivery systems for food applications: In vitro behavior, Adv. Colloid Interface Sci., 2017, 243, 23-45.

19 M. Minekus, M. Alminger, P. Alvito, S. Ballance, T. Bohn, C. Bourlieu, F. Carriere, R. Boutrou, M. Corredig, D. Dupont, C. Dufour, L. Egger, M. Golding, S. Karakaya, B. Kirkhus, S. Le Feunteun, U. Lesmes, A. Macierzanka, A. Mackie, S. Marze, D. J. McClements, O. Menard, I. Recio, C. N. Santos, R. P. Singh, G. E. Vegarud, M. S. J. Wickham, W. Weitschies and A. Brodkorb, A standardised static in vitro digestion method suitable for food - an international consensus, Food Funct., 2014, 5, 1113-1124.

20 A. Brodkorb, L. Egger, M. Alminger, P. Alvito, R. Assuncao, S. Ballance, T. Bohn, C. Bourlieu-Lacanal, R. Boutrou, F. Carriere, A. Clemente, M. Corredig, D. Dupont, C. Dufour, C. Edwards, M. Golding, S. Karakaya, B. Kirkhus, S. Le Feunteun, U. Lesmes, A. Macierzanka, A. R. Mackie, C. Martins, S. Marze, D. J. McClements, O. Menard, M. Minekus, R. Portmann, C. N. Santos, I. Souchon, R. P. Singh, G. E. Vegarud, M. S. J. Wickham, W. Weitschies and I. Recio, INFOGEST static in vitro simulation of gastrointestinal food digestion, Nat. Protoc., 2019, 14, 991-1014.

21 Y. P. Timilsena, J. Vongsvivut, M. J. Tobin, R. Adhikari, C. Barrow and B. Adhikari, Investigation of oil distribution in spray-dried chia seed oil microcapsules using synchrotron-FTIR microspectroscopy, Food Chem., 2019, 275, 457466.
22 M. George and T. E. Abraham, Polyionic hydrocolloids for the intestinal delivery of protein drugs: Alginate and chitosan-a review, J. Controlled Release, 2006, 114, 1-14.

23 Y. Tan, Z. Zhang, J. Muriel Mundo and D. J. McClements, Factors impacting lipid digestion and nutraceutical bioaccessibility assessed by standardized gastrointestinal model (INFOGEST): Emulsifier type, Food Res. Int., 2020, 137, 109739.

24 C. I. Piñón-Balderrama, C. Leyva-Porras, Y. Terán-Figueroa, V. Espinosa-Solís, C. Álvarez-Salas and M. Z. Saavedra-Leos, Encapsulation of active ingredients in food industry by spray-drying and nano spray-drying technologies, Processes, 2020, 8, 889.

25 H. Yoshida, I. Kondo and G. Kajimoto, Participation of free fatty acids in the oxidation of purified soybean oil during microwave heating, J. Am. Oil Chem. Soc., 1992, 69, 11361140.

26 AOCS, Official methods and recommended practices of the American Oil Chemists Society, American Oil Chemists Society, Champaign, IL, 3rd edn, 1993.

27 S. Guerrero, M. Inostroza-Riquelme, P. Contreras-Orellana, V. Diaz-Garcia, P. Lara, A. Vivanco-Palma, A. Cárdenas, V. Miranda, P. Robert, L. Leyton, M. J. Kogan, A. F. G. Quest and F. Oyarzun-Ampuero, Curcumin-loaded nanoemulsion: a new safe and effective formulation to prevent tumor reincidence and metastasis, Nanoscale, 2018, 10, 22612-22622.

28 Y. Z. Cai and H. Corke, Production and properties of spraydried Amaranthus betacyanin pigments, J. Food Sci., 2000, 65, 1248-1252.

29 J. Yang and O. N. Ciftci, In vitro bioaccessibility of fish oilloaded hollow solid lipid micro- and nanoparticles, Food Funct., 2020, 11, 8637-8647.

30 N. Ng, P. X. Chen, S. M. Ghazani, A. J. Wright, A. Marangoni, H. D. Goff, I. J. Joye and M. A. Rogers, Lipid digestion of oil-in-water emulsions stabilized with low molecular weight surfactants, Food Funct., 2019, 10, 81958207.

31 P. de Vos, M. M. Faas, M. Spasojevic and J. Sikkema, Encapsulation for preservation of functionality and targeted delivery of bioactive food components, Int. Dairy J., 2010, 20, 292-302.

32 R. Partanen, P. Hakala, O. Sjövall, H. Kallio and P. Forssell, Effect of relative humidity on the oxidative stability of microencapsulated sea buckthorn seed oil, J. Food Sci., 2005, 70, E37-E43.

33 A. Gharsallaoui, G. Roudaut, O. Chambin, A. Voilley and R. Saurel, Applications of spray-drying in microencapsulation of food ingredients: An overview, Food Res. Int., 2007, 40, 1107-1121.

34 J. J. Luna-Guevara, C. E. Ochoa-Velasco, P. HernándezCarranza and J. A. Guerrero-Beltrán, Microencapsulation of walnut, peanut and pecan oils by spray-drying, Food Struct., 2017, 12, 26-32.

35 A. H. Barrett, W. L. Porter, G. Marando and P. Chinachoti, Effect of various antioxidants, antioxidant levels, and encapsulation on the stability of fish and flaxseed oils: 
assessment by fluorometric analysis, J. Food Process. Preserv., 2011, 35, 349-358.

36 R. V. Tonon, R. B. Pedro, C. R. Grosso and M. D. Hubinger, Microencapsulation of flaxseed oil by spray-drying: Effect of oil load and type of wall material, Drying Technol., 2012, 30, 1491-1501.

37 C. Aspargaus, P. John, A. Collenberg and D. Rütti, Nanocapsules formation by nano spray-drying, in Nanoencapsulation technologies for the food and nutraceutical industries, ed. S. M. Jafari, Academic Press, 2017, pp. 346-401.

38 M. Geranpour, E. Assadpour and S. M. Jafari, Recent advances in the spray-drying encapsulation of essential fatty acids and functional oils, Trends Food Sci. Technol., 2020, 102, 71-90.

39 G. Gallardo, L. Guida, V. Martínez, M. C. López, D. Bernhardt, R. Blasco, R. Pedroza-Islas and L. G. Hermida, Microencapsulation of linseed oil by spraydrying for functional food application, Food Res. Int., 2013, 52, 473-482.

40 S. D. Reid and O. R. Fennema, Water and ice, in Fennema's Food Chemistry, ed. S. Damodaran, K. L. Parkin and O. R. Fennema, Taylor \& Francis Group, Boca Raton, 4th edn, 2008, pp. 17-83.

41 M. A. Abd El-Ghaffar, M. S. Hashem, M. K. El-Awady and A. M. Rabie, pH-sensitive sodium alginate hydrogels for riboflavin controlled release, Carbohydr. Polym., 2012, 89, 667-675.

42 P. J. Wilde and B. S. Chu, Interfacial \& colloidal aspects of lipid digestion, Adv. Colloid Interface Sci., 2011, 165, 14-22.
43 L. Salvia-Trujillo, C. Qian, O. Martín-Belloso and D. J. McClements, Influence of particle size on lipid digestion and $\beta$-carotene bioaccessibility in emulsions and nanoemulsions, Food Chem., 2013, 141, 1472-1480.

44 Z. Ye, R. Li, C. Cao, Y. J. Xu, P. Cao, Q. Li and Y. Liu, Fatty acid profiles of typical dietary lipids after gastrointestinal digestion and absorbtion: A combination study between in vitro and in vivo, Food Chem., 2019, 280, 34-44.

45 Q. Guo, A. Ye, N. Bellissimo, H. Singh and D. Rousseau, Modulating fat digestion through food structure design, Prog. Lipid Res., 2017, 68, 109-118.

46 M. M. C. de Almeida, C. R. L. Francisco, A. de Oliveira, S. Silva de Campos, A. P. Bilck, R. H. Barros Fuchs, O. H. Gonçalves, P. Valderrama, A. K. Genena and F. V. Leimann, Textural, Color, Hygroscopic, Lipid Oxidation, and Sensory Properties of Cookies Containing Free and Microencapsulated Chia Oil, Food Bioprocess Technol., 2018, 11, 926-939.

47 R. Ullah, M. Nadeem, M. Imran, M. K. Khan, Z. Mushtaq, M. Asif and A. Din, Effect of microcapsules of chia oil on Q-3 fatty acids, antioxidant characteristics and oxidative stability of butter, Lipids Health Dis., 2020, 19, 10.

48 N. K. Mohammed, C. P. Tan, Y. A. Manap, B. J. Muhialdin and A. S. M. Hussin, Spray-drying for the encapsulation of oils-a review, Molecules, 2020, 25, 3873.

49 A. González, M. G. Bordón, M. C. Bustos, K. L. Córdova Salazar, P. D. Ribotta and M. L. Martínez, Study of the incorporation of native and microencapsulated chia seed oil on pasta properties, Int. J. Food Sci. Technol., 2021, 56, 233-241. 